\title{
The Strengths Model: Birth to Toddlerhood
}

\author{
Charles A. Rapp \\ W. Patrick Sullivan
}

\begin{abstract}
The Strengths Model/Perspective was developed by social workers and the profession continues to be the leader in its practice, research and refinement. This article traces the three decades of evolution of this approach and the continuing expansion of its use around the world. Cautionary notes are provided and an agenda for future development is proposed.
\end{abstract}

Keywords: Strengths model, strengths perspective, case management, strengths model fidelity, strengths model and social work

The Strengths Model/Perspective has just passed its $30^{\text {th }}$ birthday and has continuously attracted the interest of many practitioners, administrators, and scholars. While social work remains the lead profession interested in the Strengths Model/Perspective and mental health its most well-developed field of practice, the breadth of its appeal has been quite surprising, involving various helping professions, and a wide group of fields of practice. The new millennium has been marked by a broadening of worldwide interest in strengths based approaches (Francis, Pulla, Clark, Mariscal, \& Ponnuswami, in press; Pulla, Chenowith, \& Francis, 2012).

It might be a propitious time to reflect on the origins of the model and its evolution. Thirty years, from the perspective of human development, is a significant time span. However, when it comes to the world of big ideas, things we call perspectives or paradigms generally take far more than three decades to simply sketch out the questions that need to be addressed. We see the strengths perspective in just that light. Unquestionably for some, thinking in terms of strengths, particularly in direct practice settings has become routine and accepted. Because of this, there is the inevitable quest to search for what is new and novel, and some may now view this once radical approach as passé.

Even the most fervent strengths model adherents must avoid being caught in a trap. Nothing can breed complacency more than success. Indeed, in some respects, given humble beginnings in pilot mental health projects, to expansion to other fields of practice, and from adoption by few bold organizations across the country, to application across the globe, the strengths model has been an unqualified hit. This creates two significant challenges. First, because the adoption of some strength principles in practice has become so commonplace it may be assumed that the messy development work has been completed. It has not. Not only are there questions left to be answered, but there is evidence of the predictable drift and reinvention that follows any innovation. Such modifications can be positive, but at times the slightest of changes can fundamentally alter the basic values and behaviors that undergird a process or practice.

Charles A. Rapp, Ph.D., is a Research Professor in the School of Social Welfare at the University of Kansas in Lawrence, KS. W. Patrick Sullivan, Ph.D., is a Professor in the Indiana University School of Social Work in Indianapolis, IN. 
The second challenge is to continue to develop and refine the core principles through solid research and draw from this intelligence to develop a reliable litmus test to discriminate what is truly strength-based approaches from those that do little more than merely draw on a subset of principles and practice. The reason for this is simple. Over time it has become apparent that there are many individuals and organizations who claim to draw from the strengths model when their values, attitudes, and behaviors tell a different tale.

Because there is so much left to do, we believe that the Strengths Model has only moved from infancy to beginning toddlerhood. Toddlerhood is generally characterized as a period of rapid learning, improved skills, and greater ability to precisely articulate one's thoughts. These challenges for the toddler are somewhat parallel to the challenges that confront the future of the strengths model and we will offer thoughts on the agenda that lies ahead.

\section{Gestation of an Idea}

February 5, 2013 marked the $50^{\text {th }}$ anniversary of a noteworthy benchmark in the history of mental health care in this nation. In a 1963 special message to Congress, President Kennedy introduced what he deemed a bold new approach to mental illness. After contentious debates and exhaustive reports had been offered, community mental health centers were opened for business across the land. Unquestionably, Kennedy's remarks reflected the optimism of the times - an era where dreaming big was nearly commonplace. In his message, the President confidently asserted that new tools and new methods were in place to offer care to those facing emotional disorders closer to home, and in fact, that prevention and early treatment could reduce the reliance on a state psychiatric system. What's more, it was felt in some quarters that some state psychiatric hospitals, both by virtue of their physical condition and overall quality of care, had become a national disgrace (Foley \& Sharfstein, 1983).

Soon after the doors of these centers opened to the public, it became clear that there was a strong demand for local mental health services. People arrived troubled by depression and anxieties, marital woes, and concerns about their children. Judged by popularity alone, the new community mental health centers were an unqualified success. Yet, as is always the case in new ventures like this, the bottom line was far more nuanced. What became painfully clear was that community mental health centers were not well-positioned to effectively serve those facing schizophrenia, bi-polar disorder, major depression and the host of serious illnesses that were found on the rolls of every state psychiatric hospital. Additionally, within a decade, key legal decisions rendered entrance to institutional care more difficult, and with relatively new programs like Medicaid and Medicare now operational, state authorities seized on the opportunity to reduce budgetary pressure by closing and downsizing institutions under their purview (Mechanic \& Rochefort, 1990).

As a result of these and other forces, the glow that once surrounded communitybased mental health services began to fade. All social problems emerge from myriad causes, but in the act of accounting and assessing causation it seems simplistic 
explanations are always embraced. Therefore, homelessness, crime, the growth of so called psychiatric ghettos, and even the existence of a young cohort clearly struggling but resistant to care was laid at the doorstep of community mental health, as well as a diverse set of circumstances labeled retrospectively as deinstitutionalization (Mechanic \& Rochefort, 1992). Clearly there was no single policy, department, or institution to blame for what appeared to be a crisis. Those challenged by serious mental illness were no longer hidden in far away institutions but found in suburbia and Main Street. Families were increasingly called upon to care for loved ones, often by the same authorities who once erroneously blamed them as the cause of illness. Many of these same weary and frustrated family members spearheaded the creation of an organization called the National Alliance for the Mentally Ill and demanded that changes be made. Clearly, something had to be done.

Einstein was said to have remarked that we cannot solve the problems we currently face with the same thinking we used in creating them. However, in so many ways this appeared to be the operating manual as community mental health ramped up services to deal with those who had once resided in state psychiatric hospitals, and those who would have once been an inpatient in a different age. Therapy, treatment and skills groups, and medications management however were the same as what had been offered before. The hospital, as a total institution, ensured that an individual's basic needs were met, and daily life was marked by a predictable routine and structure. In the community, the basic necessities of life were no longer guaranteed, and beyond family, few were tasked with the responsibility to help. It became apparent to many stakeholders that if we were to be successful, standard treatment services alone were insufficient. Indeed, to be successful, attention must be devoted to the total life of the individual. In response, by the late 1970s the National Institute of Mental Health introduced the Community Support Program, an early attempt to develop a system of care model designed to address the needs of those deemed chronically mentally ill (Turner \& TenHoor, 1978). A centerpiece of this new model of care was case management.

\section{Birth}

Sometimes things just fall into place. The forces described above stimulated efforts to develop new practice models and new systems of care. In 1982, the University of Kansas School of Social Welfare secured a $\$ 10,000$ grant from the state mental health authority to develop a model of case management. Ronna Chamberlain had arrived as a Ph.D. student after years of experience in the mental health field, particularly with those we

now deemed psychiatrically disabled. Once in Lawrence, Ronna joined faculty member Charlie Rapp who came to Kansas with experience in child welfare working with those children whom others were prepared to cast aside. Working backwards, Rapp and Chamberlain first devised a list of desirable client outcomes based on the most common goals stated by clients. It was noteworthy that these went beyond compliance and maintenance but looked to real life outcomes in key areas such as vocational activity, independent living, social support including satisfying use of leisure time and affiliation. What became clear when analyzing the state of the art in case management was how ill suited current models were positioned to address these basic human needs let alone help 
attain goals that went beyond the necessities for survival. Instead, most models viewed a case manager as a broker of service with a primary role of linking people to standard mental health services and a truncated set of auxiliary social services. Embedded in these models were low expectations for client success. The focus here was on maintenance and protection, and any notions of the possibility of recovery and citizenship were well over the horizon. It was time to roll up the sleeves and try to do something totally different.

During the earliest stages of their work, Chamberlain and Rapp discovered that there were more commonalities in their past experiences than differences. Chamberlain had been experimenting with a strengths perspective while a social worker in a state psychiatric hospital. As Chamberlain (1992) wrote about an early attempt:

Jack, a lovable guy with more hospitalizations than anyone could count, wanted to work but had no job skills. He was quite adept at group therapy, however, having had more experience than even the clinical staff. In fact, he was wonderful at supporting other clients, helping to assuage their anxiety. With a lot of help he ultimately landed a job as a work crew supervisor in a vocational training program for people with psychiatric disabilities. There he spent his days helping people through their anxiety and symptoms so that they could accomplish their tasks. He stopped using the hospital. When that program lost its funding, he went on to a different job and eventually got married (p. xiii).

Her focus was on the strengths of the individual but implicit in her work was an unrecognized view of the environment. Rapp, based on earlier work in child welfare and juvenile justice, had proposed that all environments contain a wealth of resources, that a person's behavior is mightily influenced by the resources available to people, and that our society values equal access to resources (Davidson \& Rapp, 1976). Both sets of ideas from Chamberlain and Rapp placed the client's wishes and desires front and center. Thus, less attention was directed to the identified challenge or problem, and more effort was expended towards the practical and tangible assistance and support people needed in the quest to reach their individual goals.

Chamberlain and Rapp firmly believed that merely linking clients to low expectation services that focused on remediating perceived deficits and often separated people from the community, and then blaming them for not doing better was a poor basis upon which to design a helping service. What later became known as the strengths model was based on six fundamental ideas or principles:

1. People with Psychiatric Disabilities Can Learn, Grow and Change

2. The Focus is on Individual Strengths Rather than Deficits

3. The Community is Viewed as an Oasis of Resources

4. The Client is the Director of the Helping Process

5. The Worker-Client Relationship is Primary and Essential

6. The Primary Setting for Our Work is the Community 
These ideas were different (if not the opposite) from the prevalent beliefs and practices at the time.

Armed with a mimeographed set of principles, a new tool devoted to identifying individual and environmental strengths, and a simple form used to record and monitor individual goals, the Resource Acquisition model of case management was launched. It was an interesting marriage as undergraduate and graduate social work students began to build a caseload, take the nearly unprecedented step of working in the home and community, and work on goals that the clients identified as important. Even more radical for the times, project case managers were never informed of the diagnosis of individuals they served to avoid negative expectations and stereotypes that inevitably accompanied these terms. Mental Health Center leadership was, at times, uneasy. For example, early into the project, concerns were raised when it became apparent that clients began calling student-case managers when they were in need or in crisis rather than their primary therapist. The significance of this piece of data was that it underscored the power of the case management relationship, one that was fostered by work driven by a partnership and enacted in real world settings.

After the initial project showed promise (Rapp \& Chamberlain, 1985), additional pilots were established in greater Kansas City and in Topeka, Kansas. Soon it became clear that this unique model of case management was enjoying some success, and to the surprise of many, often with individuals deemed by others to be the most impaired and the most in danger of returning to institutional care (Modrcin, Rapp, \& Poertner, 1988; Rapp \& Wintersteen, 1989). Not without struggle, others began to see the utility of this approach to case management and by the mid-1980's the state of Kansas required that all case managers be trained in the model.

Before long, others took notice of what was happening in Kansas. The appeal of the new model of case management was buttressed by its fidelity with predominant social work values. Soon the core participants in the development of the model were offering two-day workshops across the country. To say that ideas like working in the home and community instead of the office, focusing primarily on strengths in people and the world around, and building care plans from the stated goals of the recipients was a hard sell is a vast understatement. There were moments when the resistance was palpable. It was not uncommon for people to walk out of training sessions shaking their heads and visibly angry. However, some key stakeholders did get on board, and many began to feel deeply that the new model held much promise.

\section{Infancy}

What followed from here was perhaps unexpected. As Ph.D. students at the University of Kansas School of Social Welfare, who were involved with the strengths model projects, began to describe their work, others began to take notice. Ann Weick, who held a longstanding interest in philosophical frameworks that undergird social work practice, became intrigued by this new model of case management and foresaw implications that went beyond work with those facing serious mental illness. She challenged her students to dig deeper into the work, and began to take a greater interest in 
the work being done in mental health. Soon these ideas were codified in a paper that appeared in the journal Social Work titled "A strengths perspective for social work practice" (Weick, Rapp, Sullivan, \& Kisthardt, 1989).

This article would serve as the first statement for what is now known as the Strengths Model. Not surprisingly it was soon clear that kindred spirits abounded. To that end a group of educators, researchers, and practitioners were invited to participate in a small conference at the Union Building at the University of Kansas to present papers and engage in discussion. Other disciplines were represented and the potential power of a strength perspective became obvious to all attendees. Many of these papers were included in a collection edited by Dennis Saleebey and presented for the first time as The Strengths Perspective for Social Work Practice (1992).

For many, the notion of focusing on individual and environmental strengths had intrinsic appeal and resonated with a humanistic style germane to social work. Additionally, specific aspects of case management practice, from the strength assessment, to the goal and case planning method had clear utility in a range of practice settings and with the diverse populations commonly served by social workers. Before long, the strengths model was adopted in substance abuse treatment (Sullivan, Wolk, \& Hatmann, 1992). The late Harvey Siegel, Richard Rapp and colleagues at Wright State University began to extensively study the strengths model in substance abuse treatment, often with some of the most difficult of clients (Siegal et al., 1995). From that point on the possibilities were nearly endless, and ultimately went beyond direct practice to include treatises on leadership (Poertner \& Rapp, 2007) and social policy (Chapin, 2010; Rapp, Pettus, \& Goscha, 2006). In 1998, The Strengths Model: Case Management with People Suffering from Severe and Persistent Mental Illness was published as the first practice text on the model (Rapp, 1998).

\section{Towards Toddlerhood}

As the strengths movement enters toddlerhood, there are many critical developmental tasks to be undertaken. The following section proposes those tasks we deem most important in three areas: Research, fidelity and practice.

\section{Toddler: Strengths Model Research}

The research on the Strengths Model is far from conclusive yet promising. In substance abuse treatment, the strengths model has shown to improve treatment retention which is often a prerequisite for positive outcomes (Siegal, Li, \& Rapp, 2002). In other studies, improved employment outcomes and decreased involvement with the criminal justice system were found (Rapp \& Lane, 2013; Siegal et al., 1996).

Strengths case management with people with psychiatric disabilities has been investigated the most. There have been 10 studies testing this approach. Four of the studies employed experimental or quasi- experimental designs (Modrcin et al., 1988; Macias, Farley, Jackson, \& Kinney, 1997; Macias, Kinney, Jackson, \& Vos, 1994; Stanard, 1999) and six used non-experimental methods (Barry, Zeber, Blow, \& Valenstein, 2003; Fukui et al., 2012; Kisthardt, 1993; Rapp \& Chamberlain, 1985; Rapp 
\& Wintersteen, 1989; Ryan, Sherman, \& Judd, 1994). These studies have produced positive outcomes in the areas of hospitalization, housing, employment, reduced symptoms, leisure time, social supports, and family burden. The most recent study (Fukui et al., 2012) investigated the relationship between fidelity of strengths model case management implementation and the client outcomes of psychiatric hospitalization, competitive employment, involvement in post secondary education, and independent living. It found a statistically significant association between fidelity and all but independent living. This study strongly suggests that improved client outcomes are achieved as adherence to strengths model behaviors occur.

Strengths based practice continues to broaden its reach in terms of both practice applications and global interest. The principal drivers seem to be the practice community. While this is exciting, it does contribute to the paucity of research that has been published on the model. In fact, there are few areas that offer more possibilities for intervention research as the strengths perspective. A myriad of attempts to design and implement strengths based interventions with a variety of different client groups in a wide spectrum of settings (Pulla et al., 2012; Saleebey, 2013) provides many opportunities. We need to apply rigorous (as possible) research designs and measurements to these experiments. Initially, this could involve pre-post designs as a precursor to more rigorous experimental testing.

The strengths perspective is fertile ground for qualitative explorations. In its full flowering, the strengths perspective requires different approaches to engagement, assessment, case planning and interventions. There are many different pieces yet we only have one study (Kisthardt, 1993) that systematically studied clients' experience of receiving strengths-based services. If mounted in conjunction with quantitative outcome data, such an inquiry could help us explain the results we find.

\section{Toddler: Fidelity}

A prerequisite for the proposed research agenda is the development of fidelity measurement. For experimental and quasi-experimental research to be able to attribute results to the intervention, we need to know that the intervention was delivered as designed. For the qualitative research proposed, capturing the client experience must be based on the fact that they did receive the strengths-based intervention.

Currently, there is only a single fidelity instrument for strengths case management that has been tested (Fukui et al., 2012). The development of fidelity measures would also enhance strengths-based practice in two related ways. First, fidelity measurement requires us to be precise about the salient methods and elements of the intervention model. It is common for people to treat the strengths perspective as merely a slogan where such superficial behaviors as "being nice to clients" or adding two lines on strengths to an otherwise deficit based assessment is seen as being a strengths approach. We need to be better at separating the fraudulent from the real. Increased preciseness would also mightily help the design of staff training programs.

Second, fidelity measurement would enhance practice by improving quality assurance. At its core, quality assurance is a process for assessing how well service 
delivery matched the agency's prescriptions for it. Fidelity instruments would allow strengths-based service to be included in such a process. In many organizations, the frontline supervisor is a de facto core component of quality assurance and periodic fidelity measurement can be a tool for the supervisor.

\section{Toddler: Practice}

Over the last 30 years, the strengths model has gained the interest and favor by increasing numbers of practitioners, social administrators and scholars. Several books have documented the wide range of applications to different populations struggling with different challenges in a variety of countries on five continents (Francis et al., in press; Pulla et al., 2012; Saleebey, 2013). Journal articles describe additional applications (Arnold, Walsh, Oldham, \& Rapp, 2007; Cox, 2006; Yip, 2005, 2006). There are pilot projects for strengths case management being implemented in New Zealand, Hong Kong, Japan, Australia, and Canada. The growth of the strengths model belies the forces that discourage its adoption. The situation described by Saleebey (1996) almost two decades ago still stands:

Our culture and the helping professions are saturated with an approach to understanding the human condition obsessed with individual, family, and community pathology, deficit, problem, abnormality, victimization, and disorder (p. 296).

This perspective is often reflected in government rules and regulations, funding patterns and training programs for future human service personnel.

While progress continues to be made, there remains two strengths model skill sets that seem particularly challenging to develop: 1 . Translating strengths into personal plans (i.e., case plans, action plans, etc.); 2. Exploiting the strengths of the natural environment.

The purpose of an assessment is to gather information necessary for the development of a plan and its implementation to occur. We have found that teaching people to assess strengths is often attainable but more daunting is teaching them to use these strengths to fashion more powerful personal plans. In brief, a well-done strengths assessment can and should be used to identify client goals, provoke various options for pathways to goal attainment, help define specific tasks, and identify resources and social supports that can be pursued (Rapp \& Goscha, 2012). The link between the content of an individual's strength assessment and their case plan should be unambiguous.

A second area of difficulty is identifying and using naturally occurring resources in service to the client's goal. This is particularly important for populations for whom community integration is a desired purpose (e.g., various disabled populations and individuals on parole). It is still too often the case that people's perception of the strengths model is narrowly focused on the strengths of the individual excluding the strengths of the environment as the necessary compliment. Similarly, many professionals believe that segregated programs are preferred. As Sullivan (1989) wrote over two decades ago: 
Many urban areas hire recreational therapists to develop recreation programs and provide clients with a variety of opportunities to participate in active leisure-time activities. While recreation therapists clearly serve a valuable function in these programs, most rural programs do not have the luxury of hiring this type of staff person. Yet nearly every community has a gymnasium. In many small communities one can find exercise classes, and even aerobic instruction. Softball teams and leagues can be found everywhere. We must resist ideas that clients must engage in segregated activities. While the client may need help in making initial contacts and periodic support throughout the experience of engaging in community recreational activities, success is possible. Key personnel are also available to provide support for clients. High schools employ physical education instructors. Local athletes may be willing to help. All of these resources can be used to develop a good recreation program (p. 22).

The importance of recognizing and exploiting strengths in the natural environment is vitally important to social work, and is one clear area that distinguishes this disciple from others in the helping professions. First, it affirms the long standing person-inenvironment perspective that informs all phases of social work practice. Yet, so often we use this lens to help gain a greater understanding of troubling behavior, or to consider how modifications in the environment can compensate for a problem or malady. Many social programs serve as a social prosthesis to aid a person who is viewed as damaged or flawed. There is little question that this can be an important aspect of successful practice in some instances. However, rarely do we simply see the outside world as a source of strength and match the goals and desires of the person with what exists in the world around them. The idea here is to match strength with strength.

Second, because we know full well that many of those with whom we work are shunned by others, the world becomes a closed shop to them. In the case of those with serious mental illnesses, the impress of stigma is pervasive; in fact often there are only half-hearted efforts to hide this. In other populations, for example in services with older adults, the rejection can be far more subtle. We forget that the furloughed or retired banker, teacher, or older homemaker still has viable skills that can be used to their benefit and to the benefit of others. When this happens it calls forth the long standing social work commitment to advocacy and action. At issue is what Kretzmann and McKnight (1993) deemed the contribution of strangers, those who are often hidden away at the margins of society. When social resources are denied others because of their differences or due to oppressive policies and attitudes it is incumbent on social work leaders and practitioners to challenge these head on. Indeed, executed faithfully the strengths model puts the social squarely back in social work.

The following modest example demonstrates the successful use of strengths assessment information and natural community resources to help a person achieve a longstanding goal.

Dave, a 49 year old veteran of the state psychiatric system, had lived marginally and unhappily in the community for the past 7 years. It was a situation most accepted to be part and parcel of dealing with schizophrenia. In that time, he had 
been served by three case managers, lived in a squalid board and care home, and often attended a day program at the community mental health center though participating minimally. He was assigned to a new case manager who diligently, over the period of several sessions, completed a strengths assessment. Unbeknownst to the staff, and never noted in the chart, Dave had actually completed an Associate of Arts degree in business and was enrolled in an accounting program at a state university when he was first hospitalized. It began a series of revolving door treatment episodes that was finally stabilized with the help of a newer psychotropic medication. The case manager listened intently to Dave's story and asked a lot of questions about his educational experiences. The case manager noted that when talking about accounting and numbers, that Dave came alive. He liked things such as reading sports statistics, paid attention to the ups and downs of the stock market and other things that involved numbers. He said when bored he would do math problems in his head. He admitted that he was unsure if he could return to school but had always dreamed of working in a bank.

When the case manager shared what he had discovered in a team meeting others tried to quell his enthusiasm. They noted that Dave had been ill for years, his hygiene skills were minimal and he barely kept awake in groups. They suggested reluctantly that he attend a class that dealt with life skills and budgeting to see if he was truly ready to take any significant steps in his life. In short order, Dave quit coming to the center all together.

When the case manager tracked him down, Dave said he was bored and had no interest in ever going to a group again. The case manager, getting to basics asked "what do you want, and how can I help you get it." Reluctantly, Dave noted that he had made it clear numerous times, and to untold numbers of professionals, that he wanted to work in a bank. Taking him seriously the case manager and Dave began outlining steps to reach that goal. Together the case manager and Dave practiced interviewing, considered options for jobs in the area that were reasonably close to home and near a bus line. It was noteworthy that Dave's grooming began to improve without a single prompt from others. With the use of "flex funds" the case manager and Dave went to a local Goodwill where two suits were purchased. In time, and with the case manager's help, an interview was arranged at a local bank. The manager who interviewed with Dave was cognizant that some challenges existed, but was impressed with the effort that was extended and the clear desire to work. He agreed to let Dave do a part-time job he sometimes had difficulty getting done. Every day Dave came to the bank and was responsible for putting bags of loose change through a sorting machine. He loved it. He loved putting on a suit. He loved having a job. Soon he began talking about the possibility of getting his own apartment and even began contemplating returning to school part time.

The case manager honored Dave's goal and his talents with money, and exploited community resources (Goodwill, bus lines, and the bank) on behalf of achieving the goal. 


\section{Conclusion}

There continue to be forces that impede the future development of strengths-based approaches. On the other hand, there seem to be at least four factors supporting it. First, there continues to be a high level of dissatisfaction with the effectiveness of current methods, interventions and programs that seek to address the difficulties of the poor, the disabled, children and youth, offenders, the elderly and other populations served by social workers. Second, continued reductions in human service funding could force us to embrace the primacy that the strengths model places on the use of natural community resources. Third, at least in mental health, the recovery movement, now codified in the policies of the United States and many other countries, has moved the strengths model from an insurgency to main line thought. Recovery places a premium on selfdetermination, human rights, and empowerment which are all precepts of the Strengths Model. In fact, the SAMHSA Consensus Statement on Recovery (2006) included "strengths-based" as one of its 10 essential components. Recovery focuses on valuing and building on the multiple capacities, resiliencies, talents, coping abilities and inherent worth of individuals. By building on these strengths, consumers leave stymied life roles behind and engage in new life roles (e.g., partner, caregiver, friend, student, and employee). Fourth, the Strengths Approach seems to have an inherent appeal to many people. For them, the approach is hope inducing, energizing, and often highly congruent with the motivations many possessed as they entered social work and other helping professions.

The future will be determined by the people we serve. If the research shows that they achieve their goals at significantly better rates than other approaches, strengths based approaches will spread. If clients view the experiences of receiving strengths-based services as congenial, helpful and uplifting, then strengths-based approaches will continue to diffuse.

\section{References}

Arnold, E. M., Walsh, A. K., Oldham, M. S., \& Rapp, C. A. (2007). Strengths-based case management: Implementation with high-risk youth. Families in Society: The Journal of Contemporary Social Services, 88(1), 86-94.

Barry, K. L., Zeber, J. E., Blow, F. C., \& Valenstein, M. (2003). Effect of strengths model versus assertive community treatment model on participant outcomes and utilization: Two-year follow-up. Psychiatric Rehabilitation Journal, 26(3), 268-277.

Chamberlain, R. (1992). Forward. In D. Saleebey (Ed.), The strengths perspective in social work practice (pp. xiii-xiv). New York, NY: Longman.

Chapin, R. (2010). Social policy for effective practice: A strengths approach. New York, NY: Routledge.

Cox, K. F. (2006). Investigating the impact of strength-based assessment on youth with emotional or behavioral disorders. Journal of Child and Family Studies, 15(3), 278292. 
Davidson, W. S., \& Rapp, C. A. (1976). Child advocacy in the justice system. Social Work, 21(3), 225-232.

Foley, H. A., \& Sharfstein, S. S. (1983). Madness and government: Who cares for the mentally Ill? Washington, DC: American Psychiatric Press.

Francis, A., Pulla, V., Clark, M., Mariscal, S., \& Ponnuswami, I. (Eds.). (in press). Strengths based mental health care: Perspective, practice and future directions in social work.

Fukui, S., Goscha, R., Rapp, C. A., Mabry, A., Liddy, P., \& Marty, D. (2012). Strengths model case management fidelity scores and client outcomes. Psychiatric Services, 63(7), 708-710.

Kisthardt, W. (1993). The impact of the strengths model of case management from the consumer perspective. In M. Harris \& H. Bergman (Eds.), Case management: Theory and practice (pp. 165-182). Washington, DC: American Psychiatric Association.

Kretzmann, J. P., \& McKnight, J. L. (1993). Building communities from the inside out. Evanston, IL: Northwestern University.

Macias, C., Farley, O., Jackson, R., \& Kinney, R. (1997). Case management in the context of capitation financing: An evaluation of the strengths model. Administration and Policy in Mental Health and Mental Health Services Research, 24(6), 535-543.

Macias, C., Kinney, R., Jackson, R., \& Vos, B. (1994). The role of case management within a community support system: Partnership with psychosocial rehabilitation. Community Mental Health Journal, 30(4), 323-339.

Mechanic, D., \& Rochefort, D. A. (1990). Deinstitutionalization: An appraisal of reform. Annual Review of Sociology, 16(1), 301-327.

Mechanic, D., \& Rochefort, D. A. (1992). A policy of inclusion for the mentally ill. Health Affairs, 11(1), 128-150.

Modrcin, M., Rapp, C. A., \& Poertner, J. (1988). The evaluation of case management services with the chronically mentally ill. Evaluation and Program Planning, 11(4), 307-314.

Poertner, J., \& Rapp, C. A. (2007). Textbook of social administration: The consumercentered approach. New York, NY: Haworth Press.

Pulla, V., Chenoweth, L., Francis, A., \& Bakaj, S. (Eds.). (2012). Papers in strength based practice. New Delhi: Allied Publishers.

Rapp, C. A. (1998). The strengths model: Case management with people suffering from severe and persistent mental illness. New York, NY: Oxford.

Rapp, C. A., \& Chamberlain, R. (1985). Case management services for the chronically mentally ill. Social Work, 30(5), 417-422.

Rapp, C. A., \& Goscha, R. J: (2012). The strengths model: A recovery-oriented approach to mental health services. New York, NY: Oxford University Press. 
Rapp, R., \& Lane, D. T. (2013). "Knowing" the effectiveness of an evidence-based practice: Strengths-based case management with substance abusers. In D. Saleebey (Ed.), The strengths perspective in social work practice ( $6^{\text {th }}$ ed., pp. 149-160). Saddle River, NJ: Pearson.

Rapp, C. A., Pettus, C. A., \& Goscha, R. J. (2006). Principles of strengths-based policy. Journal of Policy Practice, 5(4), 3-18.

Rapp, C. A., \& Wintersteen, R. (1989). The Strengths model of case management: Results from twelve demonstrations. Psychosocial Rehabilitation Journal, 13(1), 2332.

Ryan, C. S., Sherman, P. S., \& Judd, C. M. (1994). Accounting for case manager effects in the evaluation of mental health services. Journal of Consulting and Clinical Psychology, 62(5), 965.

Saleebey, D. (Ed.). (1992). The strengths perspective in social work practice. New York, NY: Longman.

Saleebey, D. (1996). The strengths perspective in social work practice: Extensions and cautions. Social Work, 41(3), 296-305.

Saleebey, D. (Ed.). (2013). The strengths perspective in social work practice $\left(6^{\text {th }} \mathrm{ed}\right.$.). Boston, MA: Allyn and Bacon.

Siegal, H. A., Fisher, J. H., Rapp, R. C., Kelliher, C. W., Wagner, J. H., O'Brien, W. F., $\&$ Cole, P. A. (1996). Enhancing substance abuse treatment with case management its impact on employment. Journal of Substance Abuse Treatment, 13(2), 93-98.

Siegal, H. A., Li, L., \& Rapp, R. C. (2002). Case management as a therapeutic enhancement: Impact on post-treatment criminality. Journal of Addictive Diseases, 21(4), 37-46.

Siegal, H. A., Rapp, R. C., Kelliher, C. W., Fisher, J. H., Wagner, J. H., \& Cole, P. A. (1995). The strengths perspective of case management: A promising inpatient substance abuse treatment enhancement. Journal of Psychoactive Drugs, 27(1), 6772 .

Stanard, R. P. (1999). The effect of training in a strengths model of case management on client outcomes in a community mental health center. Community Mental Health Journal, 35(2), 169-179.

Substance Abuse and Mental Health Services Administration. (2006). National census statement on mental health recovery. Rockville, MD: National Mental Health Information Center.

Sullivan, W. P. (1989). Community support programs in rural areas: Developing programs without walls. Human Services in the Rural Environment, 12(4), 19-24.

Sullivan, W. P., Wolk, J. L., \& Hartmann, D. J. (1992). Case management in alcohol and drug treatment: Improving client outcomes. Families in Society, 73(4), 195-203. 
Turner, J. C., \& TenHoor, W. J. (1978). The NIMH Community Support Program: Pilot approach to a needed social reform. Schizophrenia Bulletin, 4(3), 319-349.

Weick, A., Rapp, C., Sullivan, W. P., \& Kisthardt, W. (1989). A strengths perspective for social work practice. Social Work, 34(4), 350-354.

Yip, K. S. (2005). A strengths perspective in working with people with Alzheimer's disease. The International Journal of Social Research and Practice, 4(3), 434-441.

Yip, K. S. (2006). A strengths perspective in working with an adolescent with self-cutting behaviors. Child and Adolescent Social Work Journal, 23(2), 134-146.

\section{Author note}

Address correspondence to: Charles Rapp, University of Kansas School of Social

Welfare, 1545 Lilac Lane, Lawrence, KS 66045. Email charlier@ku.edu

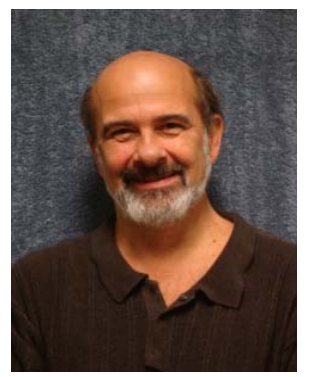

Charles A. Rapp is Research Professor at the University of Kansas School of Social Welfare and former Director of the Office of Mental Health Research and Training. He holds a Ph.D. and M.S.W. from the University of Illinois and a B.S. from Millikin University. He was one of the senior researchers with the National Evidence-Based Practice Implementation Project (2002-2005) and has been involved since in the implementation and study of evidence-based practices. He is the co-developer of strengths model of case management and the client-centered performance model of social administration. The third edition of his book, The Strengths Model: Case Management with People with Psychiatric Disabilities with Rick Goscha, was published by Oxford Press in 2011.

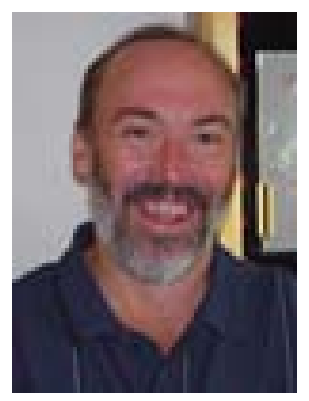

W. Patrick Sullivan serves as Professor at the Indiana University School of Social Work. He was also the Director of the Indiana Division of Mental Health and Addiction from 1994-1998. While earning a Ph.D. at the University of Kansas, Sullivan helped develop the Strengths model of Social Work practice, and has extended the model in mental health and addictions treatment and policy. He has over 70 professional publications on a diverse range of topics. He received the Distinguished Hoosier award from Governor Frank O'Bannon in 1997, and earned the Sagamore of the Wabash from Governor Joseph Kernan in 2004 for his work in mental health and addictions. Sullivan currently serves as a steering committee member for the SAMHSA/CSWE Recovery to Practice initiative and also serves on the SAMHSA/CSWE Integrated Behavioral Healthcare project. 